\title{
Behavior of Granite-Epoxy Composite Beams Subjected to Mechanical Vibrations
}

\author{
Antonio Piratelli-Filho*, Flamínio Levy-Neto \\ Departamento de Engenharia Mecânica, Faculdade de Tecnologia, \\ Universidade de Brasília - UnB, CEP 70910-900, Brasília, DF, Brasil
}

Received: July 21, 2010; Revised: October 26, 2010

\begin{abstract}
The capacity to damp mechanical vibrations is one of the most important properties of granite-epoxy composites, even superior to the cast iron one. For this reason, these materials have been adopted for manufacturing of tool machine foundations and precision instruments. This work presents a study concerning the behavior of particulate composite beams, based on granite powder and epoxy, subjected to mechanical vibrations. Composite samples were prepared with different combinations of processing variables, like the weight fraction of epoxy in the mixture and size distributions of granite particles. The damping behavior of the material was investigated adopting the logarithmic decrement method. Samples, in the form of prismatic beams, were excited in the middle point and the output signal was measured in a point located at the extremity. The obtained results showed that composite samples, with weight fractions of about $80 \%$ of granite and $20 \%$ of epoxy, presented damping properties approximately three times greater than gray cast iron.
\end{abstract}

Keywords: particulate composites, granite-epoxy, vibration damping

\section{Introduction}

The precision of Machine Tools (MT) and Coordinate Measuring Machines (CMM), used in metal-mechanical industry, is directly related with the materials used in their construction. One of the main elements of these equipments is its base or structure over which all other building components are supported. The materials specified for its manufacture must have high values of elastic modulus, yield strength, mechanical as well as wearing resistance and toughness, due to the machine intense mechanical demands. Added to these properties, it is also desirable that these materials present reduced thermal expansion coefficient and high vibrations damping capacity to perform their tasks with the required precision, thus subject to the less possible variations in response to the requirements of the operation environment.

The materials currently used that meet these properties demand are cast iron and granite. However, cast iron presents high thermal expansion and conductivity, which allow errors in the manufacturing, due to dimensional changes caused by thermal expansion and contraction and structure distortions induced by the variations in the room temperature ${ }^{1}$. The granite, a natural low cost ceramic, has low tenacity but is not easy to process due to its high hardness, porosity and internal cracks, making difficult the fabrication of complex geometry components. An additional choice mentioned in the literature is the use of concrete structures, but the reduced dimensional stability associated to water absorption makes its use unfeasible ${ }^{2}$.

Recent investigations have pointed out the use of composite materials, replacing cast iron and granite for building machine basements. Among these are the epoxy resin composites, obtained with huge amounts of granite, in the form of reduced size particles, also called epoxy-granite. Their main attractive properties are easy molding of complex geometry parts and high vibrations damping, besides their simple processing, high elastic modulus and mechanical resistance per unit weight ${ }^{3}$.
Fritz Studer was one of the pioneers in developing composites for this task and patented the Granitan compound based upon particulate granite and epoxy resin. Studer reported that, as the structural rigidity is related to the elastic modulus and the cross sections dimensions, the thickness of the machines` parts can be designed to suit operation conditions by increasing or decreasing it, as needed, keeping its resistance and even reducing the component weight, with respect to the cast iron application ${ }^{3}$.

Some companies in the Unites States supply parts manufactured with granite-epoxy compounds. The ITW Philadelphia Resins Polymer Casting Division reported a reduction in the parts production with these materials, compared with the use of cast iron. The CMS machines manufacturer observed an increase in the service life of the cutting tools and an improvement in the surface finishing of parts produced in MT constructed with granite-epoxy. European manufacturers, such as the German company ElbShliff Werkzeugmachinen, observed advantages like the reduction of the vibration and instability as function of the temperature variation, while using this material. Japanese Machinery manufacturers also have shown interest in this kind of material. In Brazil, the Romi Company produces a line of turning centers with bases made of composite synthetic granite ${ }^{3}$.

Other manufacturers in the United States are Anocast and Precision Polymer Casting. In Brazil, there is no company that produces this material, even though there exist in the market Machine Tools built up based upon synthetic granite. Other applications, besides Machine Tools, are the fabrication of optical equipments such as optical microscopes, loupes, image capturing systems, telescopes and laser instruments for medical and dental applications ${ }^{4}$.

The size, homogeneity, the ceramic particles purity and the polymers viscosity are some of the processing variables that affect the properties of these composites. The packaging, porosity and the resin`s percentage to provide high values of mechanical properties 
depend on the size and distribution of the ceramic powder particles, as well as its purity. The polymeric resin viscosity during the mixing step with the granite greatly affects the composite`s structural homogeneity, being difficult the mixing of ceramic particles with a polymeric viscous resin. Defects caused by agglomerated particles of ceramic granite (clusters) can result in reduced composite`s resistance limit ${ }^{4}$.

The damping capacity of a material is related to the dissipation of vibration energy in its internal structure, which is constantly supplied by the relative motion and friction of the parts during the operation of a Machine Tool. In general, the damping is essential to attenuate the energy produced by the source of vibration. The high damping capacity of polymers makes these materials useful for vibration absorption. Gray cast iron, which is widely used in basic Machine Tools, owes its relatively high damping capacity to the graphite lamellae observed in its microstructure.

Other researchers have supplied the basis for the development of particulate composites for applications that require vibrations damping. Li et al. ${ }^{5}$ studied vibrations damping in epoxy resin based composites. This composite, called polymeric concrete, was developed using materials such as granite and marble, plus the addition of acrylonitrile-butadiene rubber. Ohama ${ }^{6}$ presented a review on the evolution of the polymeric concrete development and classified their main applications. Fowler ${ }^{7}$ presented a view for the use of these polymeric concrete, highlighting the potential for applications in different areas.

Orak $^{8}$ developed a particulate composite with polyester polymeric resin and quartz particulate ceramic called polymeric concrete. The quartz was used in granulated strips varying from 0.5 to $8.0 \mathrm{~mm}$, with the polyester proportions fixed at $20 \%$ in weight. Vibrations damping was determined by the logarithmic decrement method, in which the measurement of the free oscillations decreasing rate must be conducted in order to determine the amount of damping present in a system: the higher the damping the higher the decline rate.

Brazilian researchers investigated granite-epoxy composites processing ${ }^{4,9-13}$. Results concerning compression resistance, equivalent to those found in similar foreign commercial materials, were obtained by studying processing variables such as particulate granite rates with different particle size and mass of granite and epoxy. However, a study on vibration damping of the involved materials is yet to be presented, being only available information from the products`suppliers.

This work presents a study on the behavior of the particulate composites based upon granite and epoxy subjected to vibrations. Probe samples (PS) of particulate granite-epoxy composites were obtained with different particle size and percentage by weight of granite, defined as process variables. The investigation of the damping properties was conducted using the logarithmic decrement technique, in which the material samples were excited at one point and the response signal was measured at the extremity of the PS.

\section{Material and Methods}

\subsection{Materials}

The composite material was prepared with powdered granite added to a cold-cured epoxy polymeric resin. The granite used was obtained from civil construction scraps in the form of plates, which were then grounded and sieved. The epoxy resin used was the YD-128, which is a diglycidyl ether of bisphenol A. The curing agent was the ANCAMIDE 805, an amine mixture.

\subsection{Probe Samples (PS) preparation}

A matrix of SAE 1020 carbon steel, type male-female, was made to mould the mixture of granite and epoxy. The array has internal dimensions of about $20 \times 20 \times 200 \mathrm{~mm}$, as to obtain samples with geometry of prismatic beams with square cross section and molded edges. The internal surfaces of the mold were cleaned and a mold release agent, Glazer Tec-N, was applied in two layers, to facilitate the removal of the sample after cure of the resin. Figure 1 shows an exploded view of the matrix constructed with the base and cover.

Preparation of granite-epoxy composite samples followed the steps shown in Figure 2. The granite slabs were broken with a Mundibra jackhammer, grounded in a Siebetechnik mill, and separated into size classes using sieves with 500, 106 and $45 \mu \mathrm{m}$ mesh. Table 1 presents the granite particles classification corresponding to the maximum and minimum sizes according to the mesh sizes of the used sieves.

Granite composites were prepared by mixing powder of two different grain sizes at $50-50 \%$ weight proportion, determined in a digital balance with $0.5 \mathrm{~g}$ resolution. Classes 1 to 4 were used to obtain the three compositions, 12, 23 and 34, which incorporate the indicated size class pairs, as presented in Tables 1 and 2 .

The samples preparation was made first adding the curing agent to the epoxy resin, at a curing agent rate of $60 \mathrm{phr}$ (parts per hundred parts of resin), giving a gel time of 1 hour and 5 minutes. After mixing, 15 minutes was the resting time established for volatilization of the curing agent components, which can hinder the granite`s wetability and could promote heterogeneity in the probe samples.

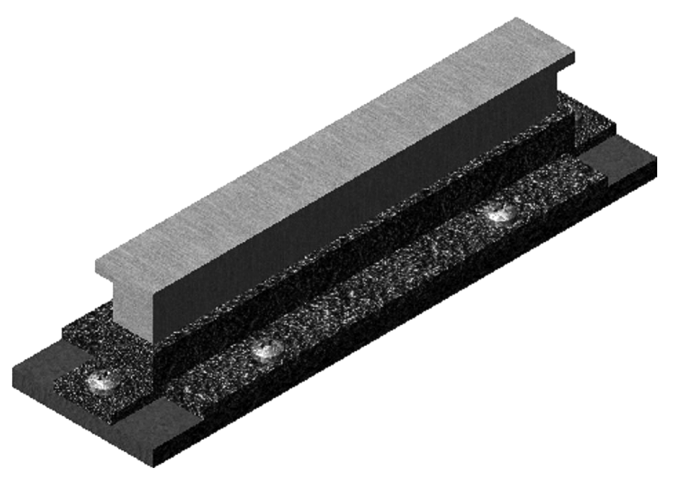

(a)

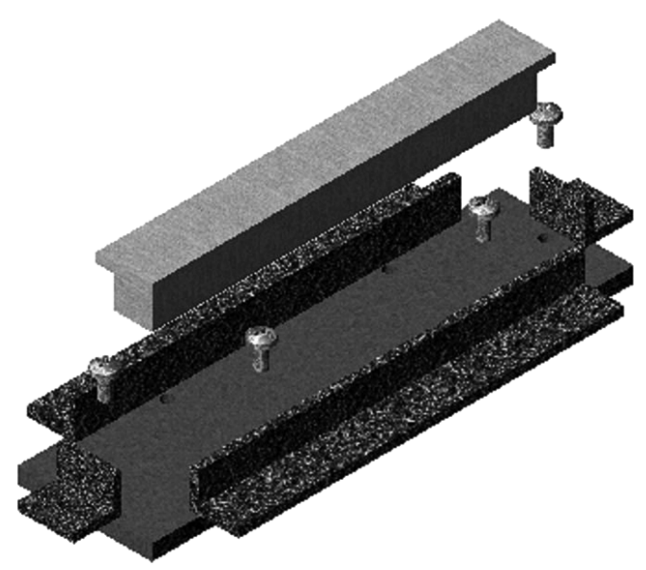

(b)

Figure 1. View of the processing matrix: a) closed; b) open for mold release and cleaning. 


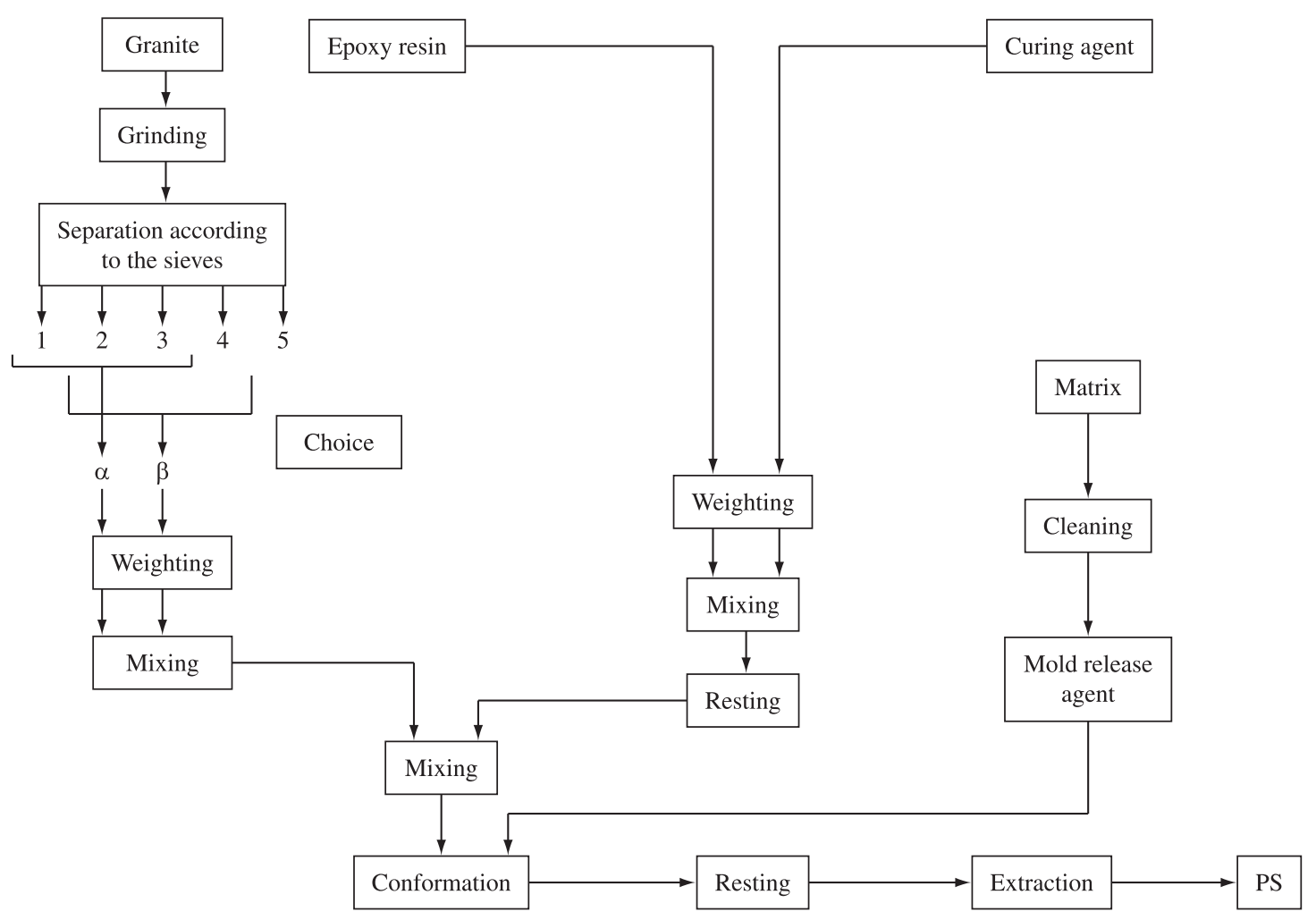

Figure 2. Probe Samples (PS) production for vibration damping tests.

Granite composites were prepared with two different epoxy ratios, 15 and $20 \%$ in weight, and the remaining was the granite composition. The material was then mixed for about 20 minutes, as to allow the wetting of the granite particles by the epoxy and the homogenization of the mixture, thus avoiding the formation of granite particles clusters.

Table 2 presents the adopted processing variables such as epoxy resin percentage and granite powder of varied sizes. The letters $\mathrm{A}$ and $\mathrm{B}$ represent the epoxy percentage, where $\mathrm{A}=15 \%$ and $\mathrm{B}=20 \%$ in weight. These values are equivalent to 26 and $33 \%$ in volume of epoxy.

The mixture was poured into the matrix in little amounts, pressing it until fulfilling the whole cavity. Next, the matrix was closed with a pressurized cover during the epoxy cure process. The probe samples were removed from the matrix after 24 hours and put under test after 7 days, the time for completing the cure. In total, 8 probe samples were obtained. A microstructure analysis was performed using a Nikon Optiphot with a system for capturing images, after sampling preparation by sanding with 180, 220, 400, 600 and 1200 mesh sandpaper and polishing with alumina $0.3 \mu \mathrm{m}$.

A sample of gray cast iron was machined with the same geometry and dimensions of the granite-epoxy samples to perform tests and to enable comparison.

\subsection{Vibration damping test}

The vibration damping test was performed with the prismatic granite-epoxy PS. Each sample was suspended at its ends with cotton yarns, to avoid rigid body movements, spreading of vibrations and noise generation in the measurement. A Brüel \& Kjaer, type 4344, piezoelectric accelerometer with $70 \mathrm{kHz}$ resonance frequency was positioned at the lower end of the PS. The accelerometer was connected to a Brüel \& Kjaer, type 2635, pre-amplifier with operation ranging from $0.1 \mathrm{~Hz}$ to $200 \mathrm{kHz}$, which in its turn was connected to a
Table 1. Granite particles size and the classification adopted for PSs.

\begin{tabular}{ccc}
\hline Minimum size $>\mu \mathrm{m}$ & Class & Maximum size $<\mu \mathrm{m}$ \\
\hline 0 & 1 & 45 \\
45 & 2 & 106 \\
106 & 3 & 500 \\
500 & 4 & 1000 \\
\hline
\end{tabular}

Table 2. Process Variables.

\begin{tabular}{cccc}
\hline PS code & \% Epoxy & \multicolumn{2}{c}{ Granite compositions } \\
\cline { 3 - 4 } & & $\mu \mathrm{m}<\alpha<\mu \mathrm{m}$ & $\mu \mathrm{m}<\beta<\mu \mathrm{m}$ \\
\hline A12 & 15 & $0<\alpha<45$ & $45<\beta<106$ \\
A23 & 15 & $45<\alpha<106$ & $106<\beta<500$ \\
A34 & 15 & $106<\alpha<500$ & $500<\beta<1000$ \\
B12 & 20 & $0<\alpha<45$ & $45<\beta<106$ \\
B23 & 20 & $45<\alpha<106$ & $106<\beta<500$ \\
B34 & 20 & $106<\alpha<500$ & $500<\beta<1000$ \\
\hline
\end{tabular}

Dynamic Analyzer HP, model 35665A and to a microcomputer. This device is shown in Figure 3. Further details can be found in literature ${ }^{14}$.

Excitations were produced by slightly knocking with a nylon tip hammer at the midpoint of the PSs, repeating this operation in each case. The resulting signal at the end, captured by the accelerometer, was recorded and saved on a file in the microcomputer.

The logarithmic decrement was adopted for analyzing the results and it was defined as a parameter equivalent to the natural logarithm of the quotient of any two consecutive amplitudes ${ }^{15}$. In this method, the determination of the damping properties involves the measuring of the experimental natural frequencies of the PS`s free vibration 
using the Fourier Fast Transform, for analysis, according to the Cooley-Tukey algorithm ${ }^{16}$. Meirovitch ${ }^{15}$ shows that the logarithmic decrement, $\delta$, can be determined by Equation 1, in which $x_{1}, x_{2}$ are two consecutive amplitudes; $x_{0}$ is any amplitude, and after $n$ cycles one obtains the amplitude $x_{\mathrm{n}}$, and $\zeta$ is the damping factor. In the case of a small damping, $\delta$ can be expressed in terms of the vibration energy $U$ and $\Delta U$ dissipated at each cycle, according to Equation $2^{[15]}$.

$$
\begin{aligned}
& \delta=\ln \frac{x_{1}}{x_{2}}=\frac{2 \pi \zeta}{\sqrt{1-\zeta^{2}}}=\frac{1}{n} \ln \frac{x_{0}}{x_{n}} \\
& \frac{\Delta U}{U}=2 \delta
\end{aligned}
$$

\section{Results and Discussion}

\subsection{Samples processing and tests results}

The displacements of the lower end of the tested PSs, presented as the average amplitudes determined with an accelerometer, are shown in Figure 4. In this graph, it is possible to observe the different behavior of the gray cast iron with respect to the granite-epoxy samples. It was noticed, initially, that cast iron presents a decrease in amplitude after 0.015 seconds, and, later, an increase of this amplitude, reaching larger values than that obtained for the granite-epoxy samples after 0.022 seconds. The curve of the sample A23 represents an average of the 3 PSs, tested with the same composition. Thus, it can be observed that only for the granite-epoxy PSs the falls in the average amplitudes are monotonic.

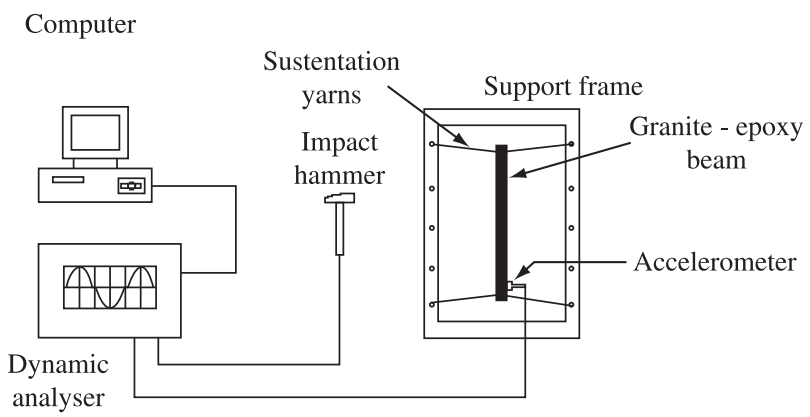

Figure 3. Experimental array for vibrations damping (adapted from Pardini et $\left.\mathrm{al} .{ }^{14}\right)$.

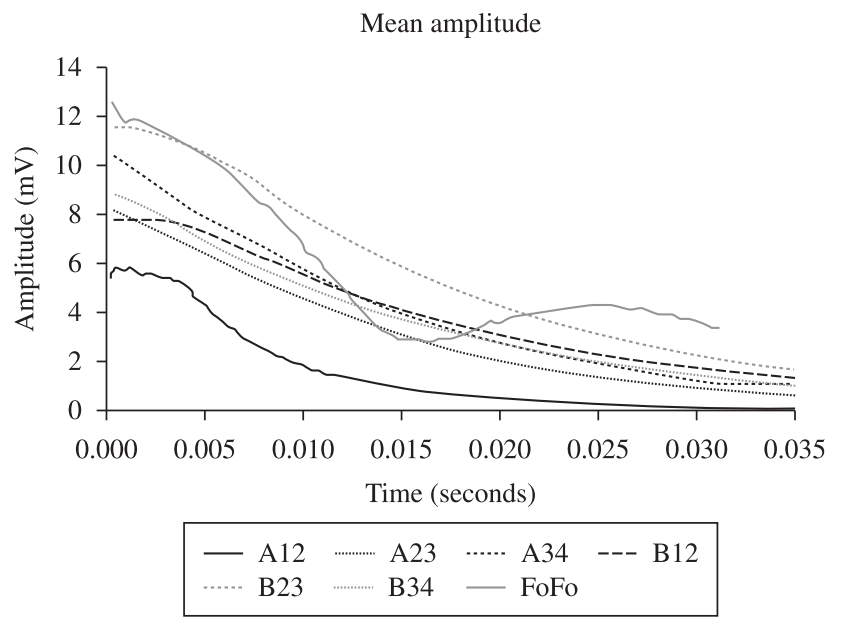

Figure 4. Mean amplitudes in function of time for each Probe-sample.

\subsection{Analysis and discussion}

\subsubsection{Spectral analysis}

Initially, for each one of the PSs, a spectral analysis of the captured points (signal in time) was conducted using Fast Fourier Transform (FFT), aiming at identifying the spectra of the frequencies involved in the tests. Figure 5 shows the signal in time of one test with the cast iron PS. Taking just the maximum point of each oscillation and calculating the average of tests on the same PS, one obtains the curve shown in Figure 4 whose respective frequency spectrum is shown in Figure 6. Here it was observed that, despite the noise variation, from zero to $4 \mathrm{kHz}$, the higher energy frequencies appear close to $2 \mathrm{kHz}$.

Figures 7 and 8 represent, respectively, the signal in time and the frequencies spectrum of a B12, PS test. It can be noted that, by comparing the graphs in Figures 6 and 8, the granite-epoxy natural vibration frequency (i.e. higher energy peak) is approximately half of that provided by the cast iron PS. In the case of cast iron, the behavior presented by the signal in time, shown in Figures 4 and 5, is probably due to the presence of two or more frequencies components, with very close values, producing the intermodulation of the frequencies and generating a beat frequency.

In Figure 6, it is noticed that the peak frequency has a relative wider base, which indicates there is not a pure frequency, but a narrow band noise. In figure 8 can be verified that there is a slight rising at around $3.4 \mathrm{kHz}$, which may indicate a second mode of vibration.

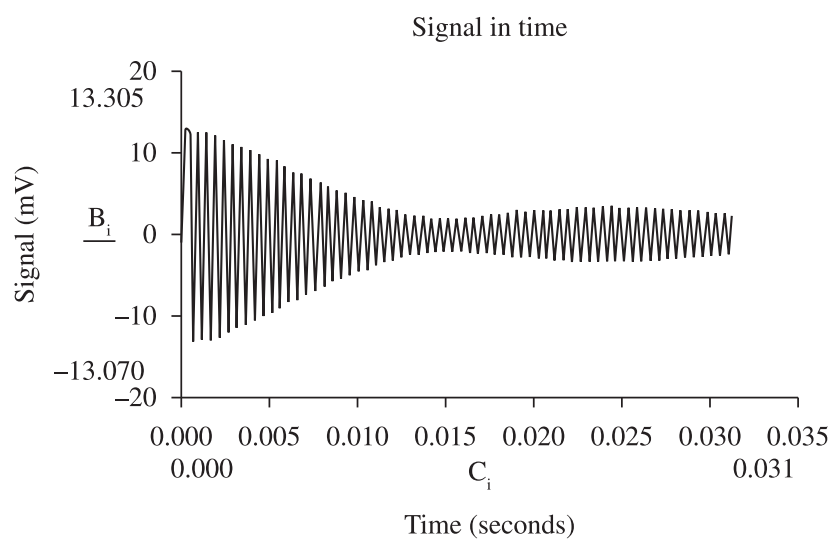

Figure 5. Signal in Time in cast iron PS.

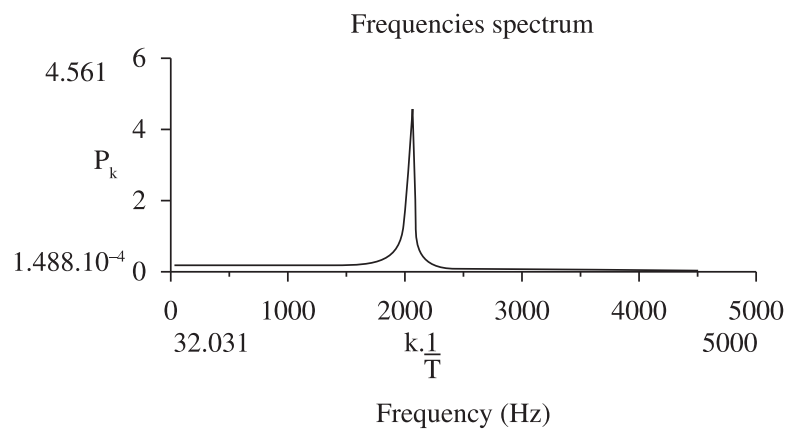

Figure 6. Frequencies spectrum of the Cast iron PS tests. 


\subsubsection{Logarithmic decrement and damping factor analysis}

Table 3 presents the calculated logarithmic decrement and average damping factor. A mean value of logarithmic decrement of 0.061 was obtained for all samples of granite-epoxy (overall average), with standard deviation of 0.012 , resulting in a coefficient of variation of almost $20 \%$. A dispersion of the obtained results can be observed in Figure 9. Concerning the A and B compositions, it was observed a slight variation in the average logarithmic decrement in function of the percentage of epoxy resin, from 0.062 (A, $15 \%$ in weight of epoxy) to 0.060 (B, 20\% in weight of epoxy), with their respective standard deviations of 0.014 and 0.007 . Despite the great dispersion of the decrement values, compared with the averages` variation, one can say that the proportion of epoxy resulted in no significant change on the damping of vibrations within the range of the studied values.

With respect to the granite powder mixture, the standard deviation varied between 0.002 and 0.026 , being the latter observed for the powder with finer grains and small percentage of epoxy resin. Therefore, no conclusion was drawn on the average effect of the mixture and the granite particles size on the vibrations damping.

The logarithmic decrement of the gray cast iron was obtained by plotting an exponential curve over the peaks of the graph, getting a representative value equivalent to 0.021 . This figure was well below all the values obtained for the granite-epoxy, whose overall average was 0.061 .

Comparing the values of the granite-epoxy composites developed in this research with those found in the literature, the maximum damping factor obtained was $1.45 \%$ and close to those presented by $\mathrm{Orak}^{8}$, which varied between 1.65 and $3.10 \%$, as a result of a processing with $20 \%$ in weight of polyester resin and $80 \%$ in weight of quartz, with grain sizes varying between 0.5 and $8 \mathrm{~mm}$. Yet, the author $^{8}$ reported a critical damping of $0.418 \%$ for the gray cast iron,

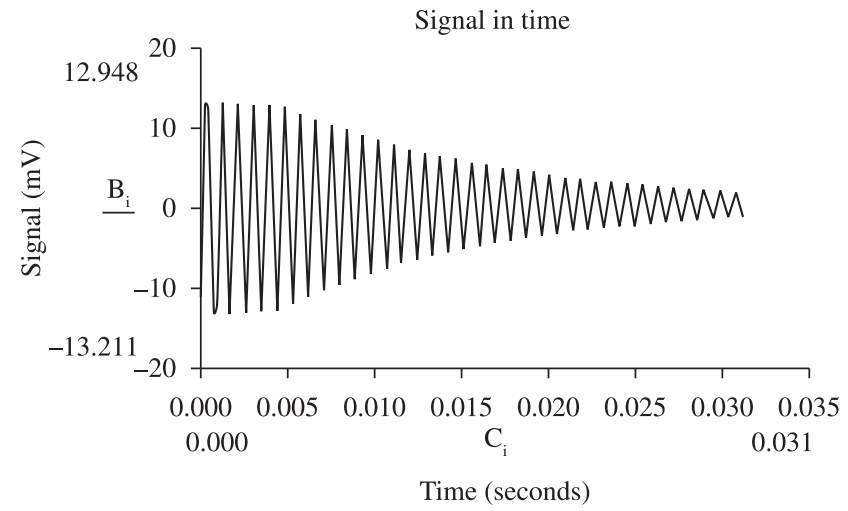

Figure 7. Signal in Time of the B12, PS.

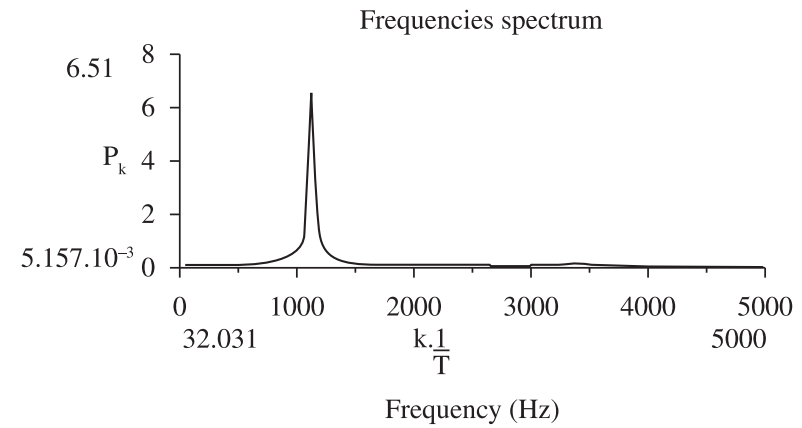

Figure 8. B12, PS test frequency spectrum. which is equivalent to a logarithmic decrement of 0.026 . The global average damping factor of the granite-epoxy samples tested in present work was $0.971 \%$ ( $0.987 \%$ for composition A, with $15 \%$ of epoxy; and $0.955 \%$ for composition B, with $20 \%$ ), which is significantly higher than $0.418 \%$ of cast iron. Li et al. ${ }^{5}$ observed that addiction of acrilonitrile-butadiene rubber with epoxy at $20 \%$ in weight and granite or limestone increases the damping factor to values between 2.18 and $2.67 \%$.

Another material that is known by its good damping capacity is graphite ${ }^{14}$. In a study in which two kinds of synthetic graphite, HLM and ATJ, were subjected to mechanical vibrations the reported values of the average damping factors were 0.724 and $0.331 \%$, respectively ${ }^{14}$. This indicates the damping capacity of both compositions of graniteepoxy investigated in the present study is superior of those of HLM graphite and cast iron.

Figure 10 shows the microstructure of a granite-epoxy sample A12, with amplification of $50 \times$. As seen, the granite particles are uniformly distributed, surrounded by epoxy resin. A few voids were observed and related to the processing steps and to the sample preparation by sanding and polishing. There were not observed clusters of granite particles with this amplification.

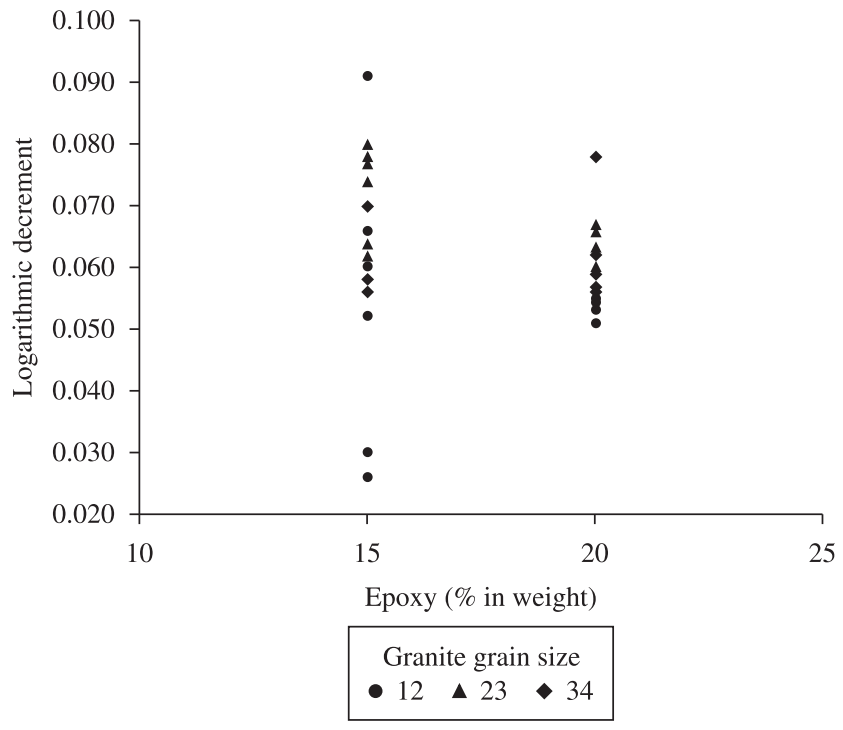

Figure 9. Logarithmic decrement of the granite-epoxy samples.

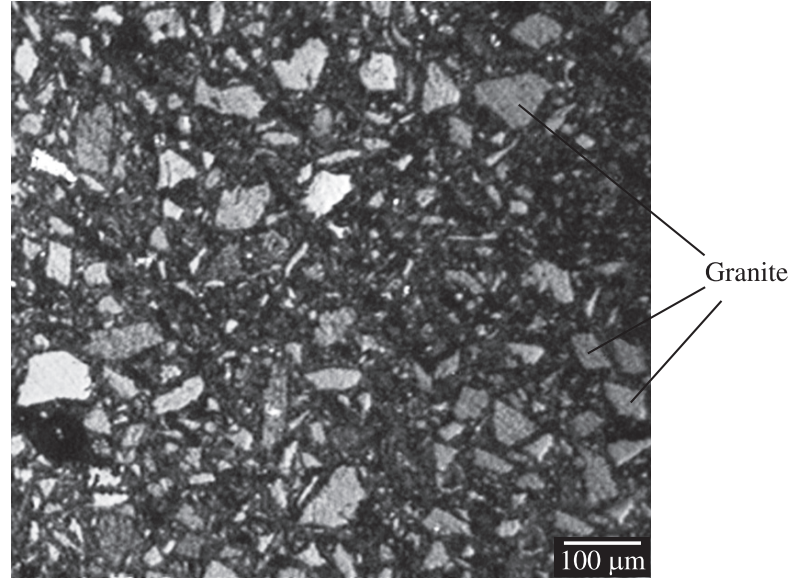

Figure 10. Micrography of granite-epoxy composite, A12 PS (50x). 
Table 3. Average logarithmic decrement and damping factor of the granite-epoxy PSs.

\begin{tabular}{|c|c|c|c|c|c|}
\hline \multicolumn{2}{|c|}{ Variables } & \multicolumn{4}{|c|}{ Results } \\
\hline $\begin{array}{l}\text { Epoxy (A) } \\
(\% \text { in weight })\end{array}$ & $\begin{array}{l}\text { Granite }(\mathrm{B}) \\
\text { grain size }\end{array}$ & $\begin{array}{l}\text { Test } \\
\text { n.o }\end{array}$ & $\begin{array}{l}\text { CP } \\
\text { n.o }\end{array}$ & $\begin{array}{c}\text { Logarithmic decrement } \\
\text { average }(\delta)\end{array}$ & $\begin{array}{c}\text { Average damping } \\
\text { factor }(\zeta) \%\end{array}$ \\
\hline & & 1 & & 0.091 & 1.45 \\
\hline & & 2 & & 0.026 & 0.41 \\
\hline & 12 & 3 & 1 & 0.052 & 0.83 \\
\hline & & 4 & & 0.030 & 0.48 \\
\hline & & 5 & & 0.058 & 0.92 \\
\hline & & 1 & & 0.061 & 0.97 \\
\hline & & 2 & & 0.056 & 0.89 \\
\hline & & 3 & 1 & 0.060 & 0.95 \\
\hline & & 4 & & 0.060 & 0.95 \\
\hline & & 5 & & 0.064 & 1.02 \\
\hline & & 1 & & 0.070 & 1.11 \\
\hline & & 2 & & 0.077 & 1.23 \\
\hline \multirow[t]{20}{*}{$15 \%$} & 23 & 3 & 2 & 0.074 & 1.18 \\
\hline & & 4 & & 0.080 & 1.27 \\
\hline & & 5 & & 0.078 & 1.24 \\
\hline & & 1 & & 0.060 & 0.95 \\
\hline & & 2 & & 0.064 & 1.02 \\
\hline & & 3 & 3 & 0.062 & 0.99 \\
\hline & & 4 & & 0.061 & 0.97 \\
\hline & & 5 & & 0.057 & 0.91 \\
\hline & & 1 & & 0.056 & 0.89 \\
\hline & & 2 & & 0.070 & 1.11 \\
\hline & 34 & 3 & 1 & 0.060 & 0.95 \\
\hline & & 4 & & 0.066 & 1.05 \\
\hline & & 5 & & 0.058 & 0.92 \\
\hline & & 1 & & 0.057 & 0.91 \\
\hline & & 2 & & 0.054 & 0.86 \\
\hline & 12 & 3 & 1 & 0.055 & 0.88 \\
\hline & & 4 & & 0.051 & 0.81 \\
\hline & & 5 & & 0.053 & 0.84 \\
\hline & & 1 & & 0.066 & 1.05 \\
\hline & & 2 & & 0.067 & 1.07 \\
\hline \multirow[t]{8}{*}{$20 \%$} & 23 & 3 & 1 & 0.063 & 1.00 \\
\hline & & 4 & & 0.060 & 0.95 \\
\hline & & 5 & & 0.066 & 1.05 \\
\hline & & 1 & & 0.062 & 0.99 \\
\hline & & 2 & & 0.056 & 0.89 \\
\hline & 34 & 3 & 1 & 0.057 & 0.91 \\
\hline & & 4 & & 0.059 & 0.94 \\
\hline & & 5 & & 0.078 & 1.24 \\
\hline
\end{tabular}

\section{Conclusion}

The logarithmic decrement values of the studied granite-epoxy samples were higher than those of cast iron, at a rate of approximately three times. This indicates that the granite-epoxy has a damping effect which is significantly higher than the gray cast iron, for the same volume of material. In addition, the damping capacity of both compositions of granite-epoxy investigated is also superior to that of HLM synthetic graphite. The amount of epoxy only influenced the dispersion of the measured values, while the samples A, with $15 \%$ in weight, provided a standard deviation of the logarithmic decrement of 0.014 , higher than the samples B with $20 \%$ in weight, equivalent to 0.007 . Concerning the granite particles size, it was not possible to verify whether there are differences, regarding the average and 
the experimental standard deviations, and neither to give a definite conclusion about its effect.

The results found were compared with the values observed in the current literature concerning vibrations damping of particulate composites for applications in machine bases. The values of the granite-epoxy damping factor and logarithmic decrement obtained in the tests were close to the respective values for composites with $20 \%$ in weight of polyester and silica, with particle size varying between 0.5 and $8 \mathrm{~mm}$. Usually, epoxy resins are more expensive than polyester resins, but when it comes to vibration damping, the results of this study suggest that the epoxy matrix should the suitable for this purpose.

Further research can be carried out using statistical tools, as factorial design, for comparison of the obtained logarithmic decrement and damping factor values as a function of the investigated variables. Considerations about the addiction of rubber to the mixture may be considered as promising variables to investigate.

\section{Acknowledgements}

The authors would like to acknowledge the Noise and Vibration Laboratory of the Department of Mechanical Engineering (ENM) of UnB for the support. In particular Professor Alberto C.G.C. Diniz and Alessandro Borges de S. Oliveira.

\section{References}

1. Bruin WD. Dimensional stability of materials for metrological and structural applications. Annals of the CIRP. 1982; 31(2):553-560.

2. Slocum AH. Precision Machine Design. New Jersey: Prentice Hall; 1992.

3. Mason F. Bases de máquinas de polímeros fundidos. Revista Máquinas e Metais. 2001; 4:64-83.

4. Piratelli-Filho A and Shimabukuro F. Characterization of compression strength of granite-epoxy composites using design of experiments. Materials Research. 2008; 11(4):399-404.
5. Li S, Hu J, Song F and Wang X. Influence of interface modification and phase separation on damping properties of epoxy concrete. Cement and Concrete Composites. 1996; 18(6):445-453.

6. Ohama Y. Recent progress in concrete-polymer composites. Advanced Cement Based Materials. 1997; 5(2):31-40.

7. Fowler DW. Polymers in concrete: a vision for the 21 st century. Cement \& Concrete Composites. 1999; 21(5-6):449-452.

8. Orak S. Investigation of vibration damping on polymer concrete with polyester resin. Cement and Concrete Research. 2000; 30(2):171-174.

9. Garcia LG and Purquério BM. Tecnologia de projeto de cabeçote hidrostático de ultraprecisão utilizando cerâmica de alumina e granito sintético. In Proceedings of the XV Congresso Brasileiro de Engenharia Mecânica-COBEM; 1999; Águas de Lindóia, SP, Brazil.

10. Felix PCG, Blazdel PF and Nogueira REFQ. Production of complex parts by low-pressure injection molding of granite powders. Part 1 preparation of feedstock, injection and debinding. In: Proceedings of the 1st Congresso Brasileiro de Engenharia de Fabricação-COBEF; 2001; Curitiba, PR, Brazil.

11. Mendonça RML, Piratelli-Filho A and Levy-Neto F. Compósitos Particulados para aplicações em engenharia de precisão: obtenção e propriedades mecânicas. In: Proceedings of the 2nd Congresso Brasileiro de Engenharia de Fabricação - COBEF; 2003; Uberlândia, MG, Brazil.

12. Campos-Rubio J, Panzera TH, Silva DM and Vilela JJ. Como obter o melhor compósito para construção de estruturas de máquinas de pequeno porte. Plástico Industrial; 2006; 9:104-115.

13. Panzera TH and Campos-Rubio J. Development of a polymeric particulate composite for precision engineering applications. CIRP Journal of Manufacturing Systems. 2006; 35:12.

14. Pardini LC, Levy Neto F and Ferreira JLA. Damping Behaviour of Synthetic Graphite Beams. Materials Research. 2006; 9(2):193-198.

15. Meirovitch L. Elements of Vibration Analysis. Sri Lanka: Tata McGrawHill Int.; 2006.

16. Bendat JS and Piersol AG. Random data: analysis and measurement procedures. 3rd ed. Los Angeles: John Willey \& Sons; 2000. 